\title{
Ultralight large grain porous material expanded obsidian
}

\author{
Artsruni Safaryan*, Tamara Sargsyan, Marine Kalantaryan and Hripsime Melyan \\ National University of Architecture and Construction of Armenia, Teryan 105, Yerevan, RA
}

\begin{abstract}
In the production of crushed stone, lithoidal pumice and perlite sand, it is advisable to separate and segregate the obsidian. Wherein, the separated obsidian is converted into production waste. By the expansion of obsidian it is possible to obtain an ultralight large grain porous material and thereby solve environmental issues - to dispose of waste products. The expansion of volcanic glass (obsidian) occurs due to gases, primary (magmatic) and secondary (hydraulic) water, which is located in the pores. During the expansion, under heat treatment, the gases expand about 4 ... 5 times in the pores, which contributes the expansion. Expanded obsidian can be used as a filler for lightweight concrete. Obsidian is expanded at temperatures of 1050-1150oC. The lowest average density of $200-350 \mathrm{~kg}$ / $\mathrm{m} 3$ (in a piece) is obtained by heat treatment of obsidian with a particle size of 5 to $20 \mathrm{~mm}$ for a duration of 3-10 minutes. Depending on the requirements for lightweight aggregates, by adjusting the firing temperature and duration, it is possible to obtain expanded obsidian with the necessary physical and mechanical properties. It is revealed that more durable concretes are obtained with cement consumption of $350 \ldots 380 \mathrm{~kg}$. Depending on the average density of lightweight concrete 400 .. 1350 $\mathrm{kg} / \mathrm{m} 3$, the compressive strength is $0.2 \ldots 16,9 \mathrm{MPa}$. Light monolithic products with improved characteristics of heat resistance and thermistance, having an average density of $180-200 \mathrm{~kg} / \mathrm{m} 3$, compressive strength of $1.2-$ 1.5 MPa, frost resistance of 25 cycles, after which the strength changes to $1.0-1.3 \mathrm{MPa}$, heat resistance to $800-850^{\circ} \mathrm{C}$, and thermistance to 600 $650^{\circ} \mathrm{C}$. By the thermal conductivity coefficient determination it was possible to reveal that in the temperature range of $20-60^{\circ} \mathrm{C}$, the thermal conductivity coefficient changes by $0.002 \mathrm{~W} / \mathrm{mK}$, i.e. from 0.044 to 0.046 $\mathrm{w} / \mathrm{mK}$. Thus, the obtained monolithic blocks can be very successfully used as heat-insulating materials, which will retain their properties throughout the operation of the facilities. The requirements for mechanical strength and decorative properties for sound-absorbing materials compared to thermal insulating materials are higher, since they are used for internal linings. Thus, the obtained monolithic blocks can be very successfully used as heat-insulating materials, which will retain their properties throughout the operation of the facilities.
\end{abstract}

\footnotetext{
"Corresponding author: artsaf5494@inbox.ru
} 


\section{Introduction}

For the development of mineral raw material production with the high content of the useful components, the industry is forced to switch to the use of poor and unconventional raw materials. The widespread use of mineral raw materials in various branches of the national economy caused a large amount of waste that poses a threat to the environment. At the same time, the quantities of associated and dump products increase exponentially. Therefore, the full use of the associated and dump products is an important economic and environmental problem. The integrated use of mineral raw materials involves not only the extraction of the valuable components, but also the development and implementation of power consumption technologies in the industry, and the processing of various associated and dump products for various materials $[1,2]$. The largest consumer of non-metallic raw materials and most of the resulting associated and dump products is only the construction industry. Therefore, associated and dump products can become anthropogenic raw materials for the production of building materials.

Anthropogenic raw materials are more energy-saturated compared to natural and traditional ones, since they undergo mechanical, chemical, thermal and other processings during the main product manufacturing. In this regard, the use of such raw materials can lead to a reduction in energy consumption, and hence the cost of the construction materials. The principles and features of anthropogenic raw material processing, as well as for the implementation of technologies for obtaining construction materials, scientifically based decisions are required. To solve this problem, attempts are being made to convert them into heat and sound insulating composites for the buildings [1,2].

During the production of crushed stone and sands from lithoid pumice and perlite, it is advisable to make separation and segregation of the obsidian. In this case, the separated obsidian is converted into production waste. Expansion of obsidian will allow to obtain ultralight large grain porous material and thereby solve environmental issues - to recycle production waste. The expansion of volcanic glass (obsidian) occurs at the expense of gases, primary (magmatic) and secondary (hydraulic) water located in the pores. During the expansion, under heat treatment the gases in the pores expand about $4 \ldots 5$ times, which contributes the expansion $[3,4]$.

Methodology

It is experimentally proved, that obsidian can be expanded at temperatures of $1000 \ldots$ $1200^{\circ} \mathrm{C}$. Above $1200^{\circ} \mathrm{C}$, partial fusion of the mass occurs. It was revealed that by the expansion of obsidian fractions of $5 \ldots 20 \mathrm{~mm}$ at a temperature of $1050 \ldots 1150 \mathrm{o}$ C for $3 \ldots$ 10 minutes it is possible to obtain an ultralight large grain aggregate with an average density of $200 \ldots 350 \mathrm{~kg} / \mathrm{m} 3$ (Fig. 1,2) [5].

Three stages of obsidian expansion can be described:

1. Expansion of obsidian by heating it up to the pyrophalic state is conditioned by the mineral melting liquid phase. In this case, the viscosity decreases dramatically, the pressure of the gas phase increases, creating excess pressure that is sufficient to overcome the viscosity and surface tension forces.

2. The expansion of volcanic glass (obsidian) occurs due to gases, primary (magmatic) and secondary (hydraulic) water, which is located in the pores. The released gaseous phase are water vapours.

3. The most important factors of the expanding process efficiency are the mass pyroclastic state and the gas phase release. The sizes of the pores caused by the expansion process is considerably dependent on the quantity of gases and their pressure. The silicate crystal expansion mechanism may be presented by the dependence on the physical and chemical parameters of pressure and melting. 
A dependence exists in an equilibrium state for the pores with $\mathbf{r}$ radius between the gas pressure of $\mathbf{p}_{\mathbf{o}}$ and the surface tension forces, which is the following:

$$
\mathbf{p}_{\mathbf{o}}=2_{\delta /} \mathbf{r}
$$

where

$\mathbf{p}_{\mathbf{o}}$ - is the gas pressure in the pores,

$\mathbf{r}$ - is the pore radius,

$\delta$ - surface tension force of the fusion,

Surface tension forces are in inversely functional dependence on the temperature, i.e. by the increase of the latter the surface tension strength decreases.

$$
\delta=1 / \mathbf{f}(\mathbf{T})
$$

The expansion of the initial pores to the $\mathrm{R}$ radius is accompanied by an increase in its surface, overcoming the viscous fluid forces, which is achieved by increasing the amount of the gas and increasing its pressure.

$$
\mathbf{R}=\mathbf{r}+\Delta \mathbf{r}
$$

The impact of the viscosity $\eta$ on the pressure value for expansion is relatively strong at the beginning, when the sizes of the initial pores are small, and the pore walls are noticeably thick.

Reduction of surface tension strength leads to the reduction of gas pressure in the pores, which promotes the occurrence of closed porosity. With the increase of the pore radius, the necessary gas pressure decreases primarily, inversely proportional to the radius,

$$
\mathbf{P}_{1}=\mathbf{1} / \mathbf{f}(\Delta \mathbf{r})
$$

Gas pressure and volume derivative P1 V1, which characterizes the gas state, increases direct proportional to the square of pore radius :

$$
P_{1} V_{1}=f(D r)^{2}
$$

The thickness of pore walls decreases inversely proportional to the square of its radius. Consequently, the gas internal pressure can exceed the strength of the pore walls, and in this case the occurance of open porosity is obvious.

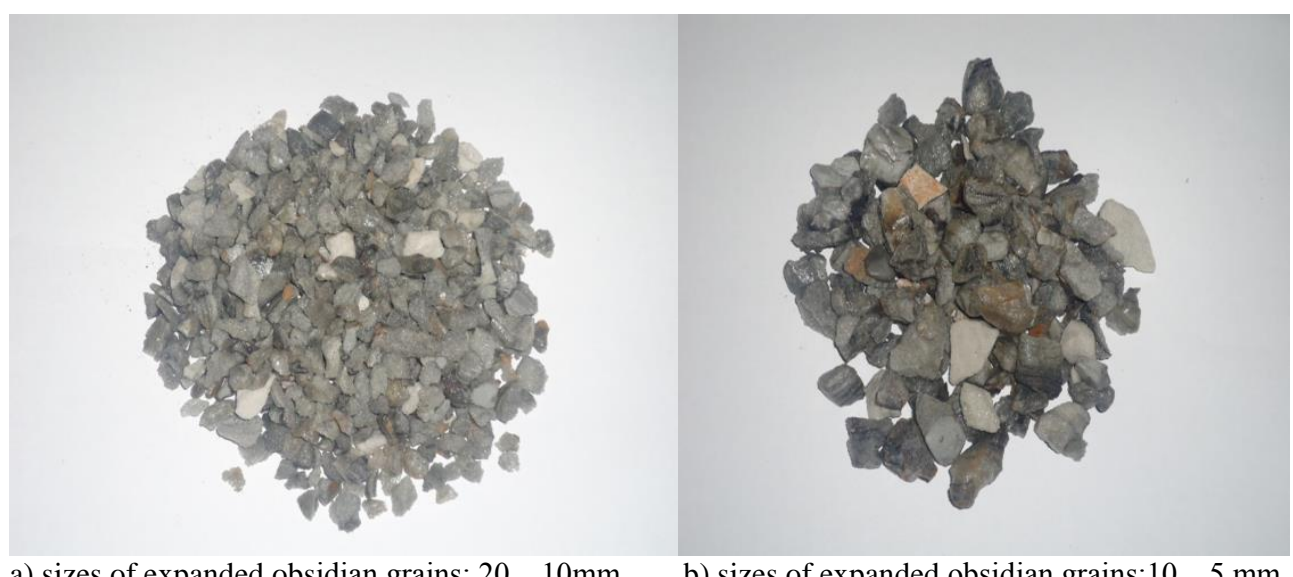

a) sizes of expanded obsidian grains: $20 \ldots 10 \mathrm{~mm}$

b) sizes of expanded obsidian grains:10...5 mm 


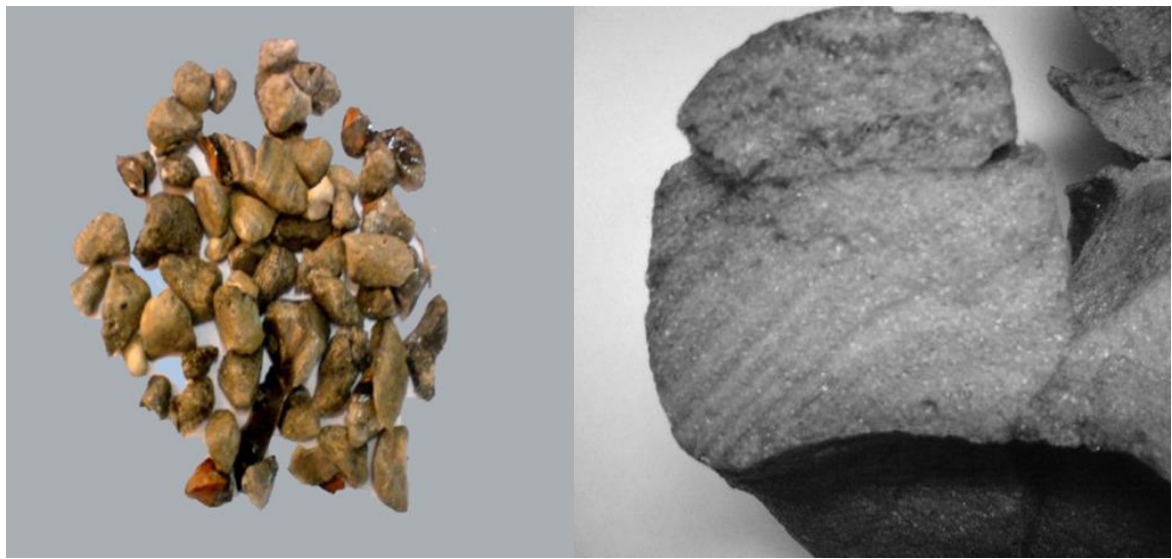

c) sizes of expanded obsidian grains: $5 \ldots 2.5 \mathrm{~mm}$

d) porosity of expanded obsidian

Fig. 1. Expanded obsidian.

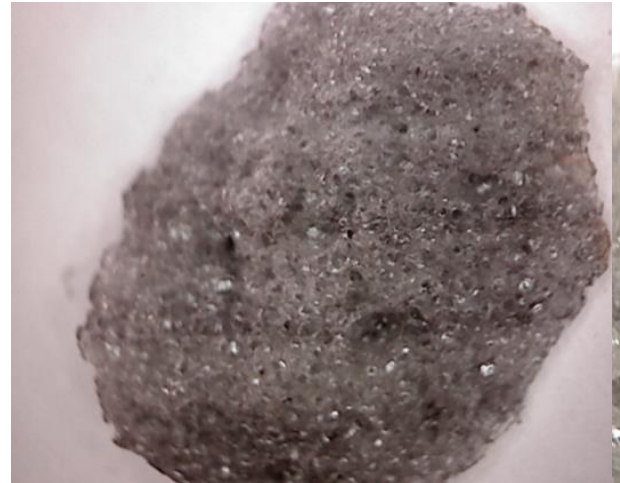

a) increased by 200 times

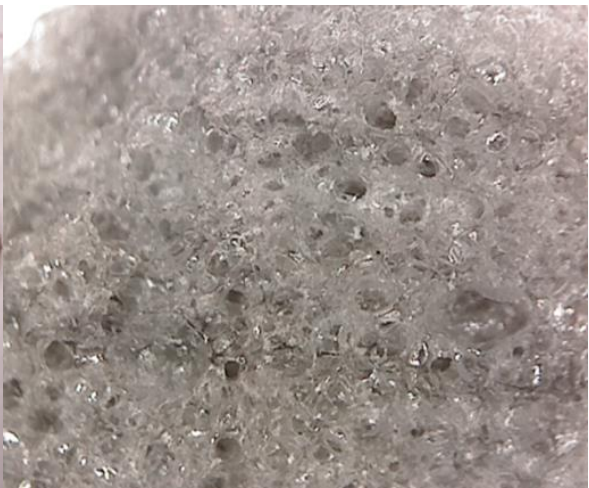

b) increased by 250 times

Fig. 2.The surface of expanded obsidian.

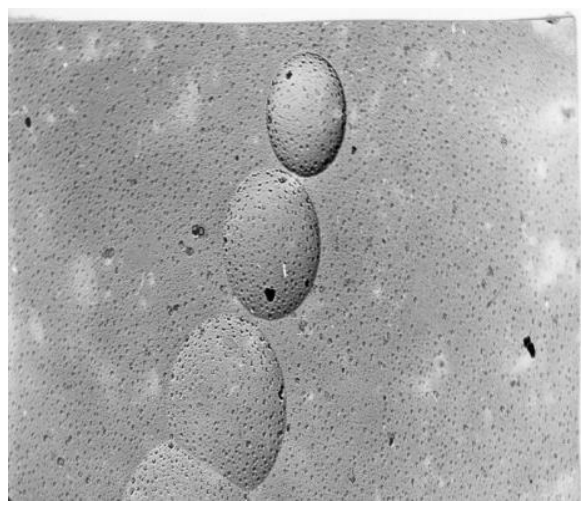

a)

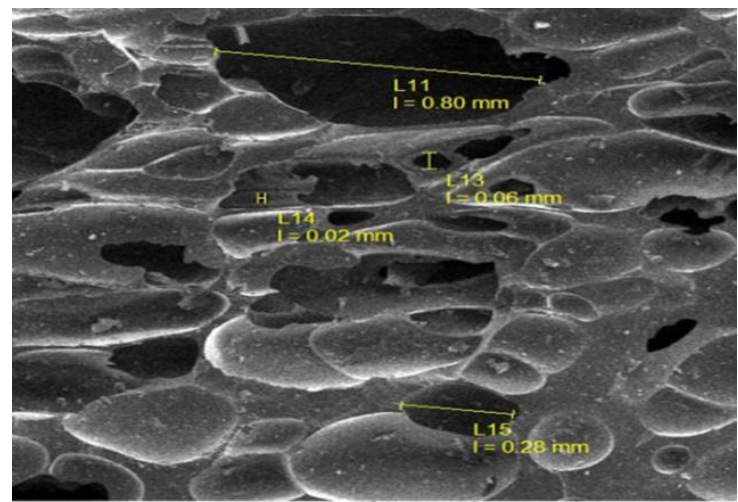

b)

Fig. 3. a) Obsidian surface before expansion b) electron microscopic image of the surface. 
Studies of the physical and mechanical properties of the lightweight large grain aggregate showed that compressive strength is $4.5 \ldots 9.9 \mathrm{MPa}$, the porosity is within $80 \ldots$ $89 \%$.

It was revealed that the strength of the expanded obsidian depends on the thickness of the interpore partitions and the surface of the particles. With an increase of the expansion coefficient, the strength decreases, and the melted surface of the particles (gravel-like) increases the strength. Water absorption of lightweight aggregate is associated with the expansion coefficient, surface and particle size.

The increased values of the expansion coefficient leads to an increase in water absorption, but the melted surface and a decrease in the size of the particles - to its reduction. Water absorption of expanded obsidian is $-10.8 \ldots 15.5 \%$ (by mass.) [3...5].

Expanded obsidian can be used as a filler for lightweight concrete [6...12]. Depending on the requirements for lightweight aggregate, by adjusting the firing temperature and duration, one can obtain expanded obsidian with the necessary physical and mechanical properties.

\section{Results}

The studies have revealed that for lightweight concretes which are based on ultralight large grain aggregate (obtained by obsidian expansion), the particle size limit is $20 \mathrm{~mm}$, while the concrete is more homogeneous compared to concrete, which uses larger particles. When using a filler with a sharply differing particle sizes, concretes with lower average density and cement consumption are obtained.

By adjusting the degree of intergranular voids, it is possible to obtain lightweight concrete based on expanded obsidian with a certain strength and medium density. More durable lightweight concrete can be obtained by increasing the proportion of fine aggregate fractions, and however at the same time the average density of concrete is increasing.

It was revealed that more durable concretes are obtained with cement consumption of $350 \ldots 380 \mathrm{~kg}$. Depending on the average density of lightweight concrete $400 . .1350 \mathrm{~kg} / \mathrm{m}^{3}$, the compressive strength is $0.2 \ldots 16.9 \mathrm{MPa}$. It is shown that lightweight concretes based on expanded obsidian and light blocks obtained by partial fusion of obsidian are thermal and frost-resistant and have a low (calculated) coefficient of thermal conductivity [13].

Light monoliths were obtained from the expanded obsidian. The results of studies on frost resistance showed that after 15 cycles, the expanded obsidian loses only $2.0 \ldots 3.4 \%$ in weight. This is due to the fact that during water saturation in the pores and capillaries of the obsidian, the air is not completely displaced, and when frozen ice crystals are formed, there is a space for growth, while they exert less pressure on the pore walls. Using the effect of partial fusion (sintering) of expanded obsidian particles, monolithic light blocks with an average density of $850 \mathrm{~kg} / \mathrm{m} 3$ and strength of $2 \mathrm{MPa}$ were obtained [14].

Lightweight monolithic products were obtained with improved characteristics of heat resistance and thermistance, having an average density of $180-200 \mathrm{~kg} / \mathrm{m}^{3}$, strength of 1.2 1.5 $\mathrm{MPa}$, frost resistance of 25 cycles, after which the strength changes to 1.0-1.3 MPa, heat resistance to $800-850^{\circ} \mathrm{C}$ and thermistance to $600-650^{\circ} \mathrm{C}$. The thermal conductivity coefficients were determined, where in the temperature range of $20-60^{\circ} \mathrm{C}$, the thermal conductivity coefficient changes by $0.002 \mathrm{~W} / \mathrm{mK}$, i.e. from 0.044 to $0.046 \mathrm{w} / \mathrm{mK}$. Thus, the monolithic blocks obtained can be very successfully used as heat-insulating materials, which will retain their properties throughout the operation of the facilities [15].

Expanded obsidian can be used as a filler for the production of fine-grained hydraulic concrete with the addition of $5 \%$ bentonite cl ay and $2 \%$ calcium chloride, which 
correspond to the B12.5 class of strength, and for water resistance and frost resistance to the grades M150, W4 and F50 [16...18].

There are higher mechanical and decorative requirements to sound-absorbing materials compared with thermal insulation materials, since they are used for internal linings in the buildings. As well as thermal insulation, they must have low water absorption, low hygroscopicity, to be fire and bioresistant. On the base of expanded obsidian, it is possible to obtain acoustic plasters with cement and gypsum with an average flexural strength of 2.229 and 5.679, and 6.2095 and 12.670 MPa for compression.

In addition, with the use of expanded obsidian it is possible to absorb oil from the water surface. The expanded obsidian with grain sizes 2,5..5,0 $\mathrm{mm}, 5,0 \ldots 10,0 \mathrm{~mm}$ and $10,0 \ldots 20,0 \mathrm{~mm}$ were used. Expanded obsidian has high sorption capacity to kerosene, transformer and machine oils, and to their mixture. The chemical modification of the expanded obsidian surface is also possible in a liquid phase. After modification the water sorption capacity decreases from 1,6 to 2,4 times, and the oil sorption capacity increases from 1,3 to 1,5 times, but for the oil mixture increased from 1.2 to 1.3 times [19,20]. After regeneration of petroleum products it is possible to use the expanded obsidian as a filler for lightweight concrete, while the physical and mechanical properties of concrete practically do not change.

\section{Conclusion}

Due to the increase in the amount of obsidian, many deposits of perlite and lithoid pumice are closed. For their further operation, it is necessary to carry out separation and segregation of obsidian. By heat treatment of separated obsidian, it is possible to obtain ultralightweight large grain porous material that can be used to produce lightweight concrete for various purposes, monolithic blocks with high thermal insulation properties, as a filler for obtaining fine-grained hydraulic engineering concrete with the addition of bentonite clay, to obtain acoustic plasters with cement and plaster, as well as a sorbent for absorption of oil from the water surface. Thus, by the involvement of anthropogenic waste in the production it would be possible to save mineral raw material consumption, and at the same time solve energy and environmental issues in this region.

This work has been carried out in the frame of "Creating the ways for sustainable urban, architectural and construction complexes development in RA and elaboration of directions with use of permanent monitoring systems" programme, financed by State Committee of Science of Republic of Armenia.

\section{References}

1. Gorbachev G.I., Bajenov Yu.M. Construction materials. - M.: Stroyizdat, 1988.- p.686 (rus).

2. Khigerovich M.I., Gorchakov G.I., Ribev I.A. etc. Construction materials. -M. High school. 1982.-p.352 (rus).

3. Safaryan A.M, Sarkisyan T.M. Bloating of obsidian- a waste product of gravel and sand production from perlite and lithoid mass- as a filler for lightweight concrete. Cooperation for solution of waste problems . Proceedings of the VII International Conference, Kharkov, Ukraine, 2010, p. 48-50. (rus).

4. V.Grigoryan, A.Safaryan, T.Sargsyan, V.Grigoryan Improvement of quality of the Armenian natural laightweight aggregates Proceedings of the 4th international conference 
on contemporary problems in architecture and construction Volume 1, September 2427,2012, Czestochowa, Poland, p. 300-303. (eng).

5. Patents of RA (The invention patents Republic of Armenia) Safaryan, A., T. Sargsyan. N2726A Method of production of light fillers. Registered in the State Register 25.03.13. (arm).

6. Hakhverdov I.N. Basics of Concrete Physics.-M.: Stroyizdat, 1981. - p.464 (rus).

7. Bajenov Yu.M. Thecnology of concrete. -M.: ACB, 2002. - p.500 (rus).

8. Bujevich G.A. Light concrete on the bases of porous fillers. -M.: Stroyizdat, 1970.p.29(rus) .

9. Zaycev Yu.V. Modeling deformation and strength of concrete by the method of fracture mechanics. -M.: Stroyizdat, 1982. - p.196 (rus).

10. Petrova K.V. Crack opening width in the elements of lightweight concrete on the poreos fillers.// Concrete and reinforced concrete, 1973, N 12, p.17-19 (rus).

11. Simonov M.Z. Basics of lightweight concrete technology. - M.: Stroyizdat, 1973. p.58 (rus) .

12. Shesperov S.V. Technology of concrete-M.: High school, 1977. P.430 (rus) .

13. Patent of RA (The invention patents Republic of Armenia) Safaryan, A., T. Sargsyan. N 2749 A raw mixture for the preparation of lightweight concretes 25-06-13 Registered in the State Register. 25.12.13. (arm).

14. Patents of RA (The invention patents Republic of Armenia) Safaryan, A., T. Sargsyan. N2787A Method of production of porous building materials. Registered in the State Register 25.06.13. (arm).

15. Zakaryan A. N., Safaryan., A. M., Sargsyan T. M. Lightweight monolithic building blocks of bloated obsidian. NUACA Bulletin, 2014,N3,p.61-65.(arm)

16. Zamchalin M.N., Korovkin M.O., Eroshkina N.A. Investigation of the effect of the bentonite additive on the properties of the solution, based on composite cement // Young Scientist. - 2015. - № 13. - p.112-115. - URL(rus).

17. Sabitov A.A. Bentonites of Russia: the state of development and prospects for the resource base development / A.A. Sabitov, E.S. Rouselik, F.A. Trofimova, A.N. Teterin // Mineral Resources of Russia. Economics and Management. 2010. № 5. p.8-17(rus).

18. Khomich V.A., Khimich T.S. Improvement of the performance properties of cement mortars with the addition of bentonite clay // Abstracts of 63 scientific conferences of the Novosibirsk Architecture and Construction Academy - Novosibirsk SibStrIN, 2006 - p. 24(rus).

19. G. Hovsepyan, A. Safaryan, M. Kalantaryan, T. Sarkisyan. Bloated obsidian as an oil sorbent. Proceedings of the $4^{\text {th }}$ international conference on contemporary problems in architecture and construction, vol.2, Czestochowa, Poland, Nov. 24-27, 2012, p. 479-482 (eng).

20. Patent of RA (The invention patents Republic of Armenia) N 2767 A G.Hovsepyan. A.Safaryan, M.Kalantaryan, T.Sargsyan N 2767A An absorbent for water surface clean up from oils.. Registered in the State Register 26.08.13. (arm). 